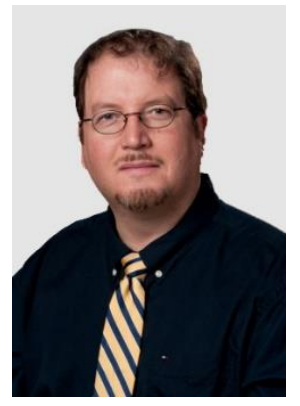

\title{
Changing Climate in the MENA Means Changing Energy Needs
}

\author{
Dr. Adam Fenech
}

The leading authority on climate change, the Intergovernmental Panel on Climate Change (IPCC) has concluded that warming of the climate system is unequivocal, and will continue for centuries. The regions in the Middle East and Northern Africa (MENA) have experienced numerous extreme climate events over the past few years including the 2009 flooding in Jeddah, Kingdom of Saudi Arabia; the 2005 dust storm in Al Asad, Iraq; water scarcity throughout the Arab MENA; and the rising sea levels on the Nile Delta coast, Egypt. A climate baseline can be developed for regions in the MENA by locating climate stations in the study area using observations made in the Global Climate Observing System (GCOS). For projections of future climate, global climate models (GCMs), mathematical equations that describe the physics, fluid motion and chemistry of the atmosphere, are the most advanced science available. The Climate Research Lab at the University of Prince Edward Island has a dataset available to researchers, called the Climate, Ocean and Atmosphere Data Exchange (COADE), that provides easy access to the output from forty global climate models used in the deliberations of the Intergovernmental Panel on Climate Change's (IPCC) Fifth Assessment Report (AR5) including monthly global climate model projections of future climate change for a number of climate parameters including temperature and precipitation. Over the past 50 years, climate changes in the MENA Region have led to increases in annual mean temperatures and decreases in annual total precipitation. Applying all four greenhouse gas emission futures on a base climate normal of 1981-2010 to an ensemble of forty global climate models used in the Fifth Assessment Report of the Intergovernmental Panel on Climate Change (IPCC AR5) results in future temperature increases for the MENA Region ranging from 1.6 to 2.3 degrees Celsius, and in a range of future precipitation changes from reductions of 11 percent to increases of 36 percent by the 2050s (2041-2070). These preliminary results should assist the MENA Region in planning its energy needs and its needs for renewable energy through increasing the understanding of how climate has impacted the region in the past, and how climate will impact in the future.

\footnotetext{
About Dr. Adam Fenech

Dr. Fenech has worked extensively in the area of climate change since the Intergovernmental Panel on Climate Change First Assessment Report in 1988. He has edited 8 books on climate change, most recently on Climate Impacts and Adaptation Science. Dr. Fenech has worked for Harvard University researching the history of the science/policy interfaces of climate change. He has represented Canada at international climate negotiating sessions; written climate policy speeches for Canadian Environment Ministers; and authored Canadian reports on climate change to the United Nations. Dr. Fenech has taught at the University of Toronto as well as the Smithsonian Institution for almost 20 years, and lectures regularly at universities across Canada and around the world. He is presently the Director of the University of Prince Edward Island's Climate Research Lab that conducts research on the vulnerability, impacts and adaptation to climate change.
} 